\title{
Predictors of COPD symptoms: does the sex of the patient matter?
}

\author{
L. Watson*, J.P. Schouten*, C-G. Löfdahl ${ }^{\#}$, N.B. Pride ${ }^{\star}$, L.A. Laitinen ${ }^{+}$and \\ D.S. Postma ${ }^{\S}$, on behalf of the European Respiratory Society Study on Chronic \\ Obstructive Pulmonary Disease
}

ABSTRACT: Although chronic obstructive pulmonary disease (COPD) patients frequently report symptoms, it is not known which factors determine the course of symptoms over time and if these differ according to the sex of the patient. The current study investigated predictors for presence, development and remission of COPD symptoms in 816 males and 312 females completing 3-yrfollow-up in the European Respiratory Society Study on Chronic Obstructive Pulmonary Disease (EUROSCOP).

The following were included in generalised estimating equations logistic regression analyses: explanatory variables of treatment; pack-yrs smoking; age, forced expiratory volume in one second \% predicted (FEV $1 \%$ pred); annual increase in $\mathrm{FEV}_{1}$ and number of cigarettes smoked; body mass index; and phadiatop. Interaction terms of sex multiplied by explanatory variables were tested.

Over 3 yrs, similar proportions of males and females reported symptoms. In males only, higher FEV 1 \% pred was associated with reduction in new symptoms of wheeze and dyspnoea, and symptom prevalence was reduced with annual $\mathrm{FEV}_{1}$ improvement and phlegm prevalence reduced with budesonide treatment (odds ratio 0.66 ; $95 \%$ confidence interval $0.52-0.83$ ). Additionally an increase in the number of cigarettes smoked between visits increased the risk of developing phlegm (1.40 (1.14-1.70)) and wheeze (1.24 (1.03-1.51)) in males but not females.

The current study shows longitudinally that symptom reporting is similar by sex. The clinical course of chronic obstructive pulmonary disease can differ by sex, as males show greater response to cigarette exposure and treatment.

KEYWORDS: Chronic obstructive pulmonary disease, lung function, sex, symptoms, treatment

$t$ is of clinical importance to understand the key factors that will influence the course of chronic obstructive lung disease (COPD). Factors that possibly alter the course and presentation of the disease include medication, antismoking advice or lung function. To apply appropriate medical interventions it is also essential to understand if there may be differences in the cause and outcome of the disease between male and female patients. Despite symptoms being one of the most troublesome features for an individual with COPD, virtually nothing is known about the sex differences in risk factors for the course of symptoms of patients with mild-to-moderate COPD. There is only limited literature that describes risk factors, such as age, smoking history and industrial exposure, for the presence, development and remission of respiratory symptoms in the general population,

For editorial comments see page 259. and in patients diagnosed with COPD who give up smoking [1-4]. In light of the increase in incidence and prevalence of COPD and its mortality in females $[5,6]$, and evidence from cross-sectional studies indicating that the presence of respiratory symptoms in COPD is associated with the sex of the patient as well as lung function, smoking and treatment [7-11], it is now imperative to investigate how these factors are longitudinally associated with the course of symptoms.

In the general population, it has been reported that females report dyspnoea and cough more frequently and phlegm less often than males [12]. This may in part be biologically driven, since females have smaller airway size [13] and a lower threshold of cough reflex sensitivity [14] compared with males. Furthermore, the sociological aspect of females not liking to admit to having phlegm may play a role in this respect [12]. A lower lung function has also been associated with the presence of respiratory symptoms, both in the
AFFILIATIONS

Depts of *Epidemiology and

Bioinformatics, and

§Pulmonology, University Medical Centre Groningen, University of Groningen, The Netherlands. \#Dept of Respiratory Medicine and Allergology, University Hospital Lund, Sweden.

"Respiratory Division, Hammersmith Campus, NHLI, Imperial College, London, UK.

${ }^{+}$Dept of Medicine, University Centra Hospital, Helsinki, Finland.

CORRESPONDENCE

D.S. Postma

Dept of Pulmonology

University Medical Centre Groningen University of Groningen

Hanzeplein 1

9731 GZ Groningen

The Netherlands

Fax: 31503613920

E-mail: d.s.postma@int.umcg.nl

Received:

May 112005

Accepted after revision:

April 242006
European Respiratory Journal Print ISSN 0903-1936 Online ISSN 1399-3003 
general population and in patients with COPD [15-17]. Since this has been established in several cross-sectional studies, the question arises as to whether longitudinal changes in forced expiratory volume in one second (FEV1) are associated with subsequent incidence and remission of symptoms, and whether this differs by sex.

Treatment with inhaled corticosteroid (ICS) is another factor that may affect symptoms of COPD, although evidence to date is inconclusive with regard to improvement in symptoms after treatment with ICS [7, 18-21]. Symptoms were not the primary outcome in any of the published long-term intervention studies with ICS in COPD patients, all of which assessed lung function as the main outcome. Sex differences were also not assessed, which may have masked differences between males and females.

Smoking is another important factor that may influence symptom incidence or remission and may show differences between the sexes. Interestingly, the Tucson Epidemiological Study combined with data from a Polish study showed that smoking cessation or reduction diminished symptoms of chronic cough, phlegm and dyspnoea by up to $50 \%$ in both sexes [3].

The differences in prevalence, incidence and remission of COPD symptoms over a 3-yr-period are reported for males and females with mild-to-moderate COPD patients using data from the European Respiratory Society Study on Chronic Obstructive Pulmonary Disease (EUROSCOP), which has already been published [19]. The current study will additionally assess the association of these key risk factors with the development or remission of symptoms.

\section{METHODS}

The design of the EUROSCOP Study has been discussed elsewhere [19]. In brief, 39 study centres in nine European countries participated in a randomised, double-blind, placebocontrolled study testing twice-daily treatment with $400 \mu \mathrm{g}$ budesonide (via Turbuhaler ${ }_{\circledast}$; AstraZeneca, Lund, Sweden) versus placebo. Patients were aged $30-65$ yrs and were currently smoking at least five cigarettes per day and had smoked cigarettes for $\geqslant 10$ yrs or had a smoking history of $\geqslant 5$ pack-yrs. They had a FEV1 post-bronchodilation between $50-100 \%$, and the ratio of pre-bronchodilator FEV1 to slow vital capacity (VC) was $<70 \%$. Increase in FEV1 after inhalation of $1 \mathrm{mg}$ terbutaline had to be $<10 \%$ of normal predicted value. Patients with a history of asthma, allergic rhinitis or who had used oral glucocorticosteroids for $>4$ weeks during the 6 months prior to study entry were excluded.

Baseline data regarding height, weight, smoking and smoking history were taken. Symptoms were measured at the baseline randomisation visit (month 0 ), with three more measurements taken at 12-monthly intervals (12 months, 24 months and 36 months post-randomisation). The symptoms analysed were as follows: 1) wheezing or whistling in the chest at any time; 2) attacks of shortness of breath after activity; 3) cough during the day or night in winter; and 4) phlegm during the day or at night in the winter. Although other symptom data, such as ever trouble with breathing, bringing up phlegm first thing in the morning in winter, and cough first thing in the morning in winter, were collected, the main symptoms chosen were considered the most clinically appropriate, were most accurate for patients to recall and occurred with high prevalence. Spirometry was performed at each visit for up to 36 months and the process is described elsewhere [19]. The largest values for slow VC and FEV1 were accepted from three manoeuvres, provided the second largest measure was within $0.1 \mathrm{~L}$ or $5 \%$ of the largest measure. FEV1 was obtained $15 \mathrm{~min}$ after the inhalation of terbutaline $(1 \mathrm{mg})$. Information regarding smoking habit was also collected at each 3-monthly visit. Specific immunoglobulin E was measured at baseline, using the Phadiatop test (Pharmacia \& Upjohn, Uppsala, Sweden).

\section{Statistical analyses}

The prevalence of symptoms at the four annual visits, and the incidence and remission between those visits were analysed using generalised estimating equations (GEE) for the binomial family with identity link and unstructured correlation structure, with clusters identified by persons [22, 23].

For the incidence and remission models, the change in symptom status was used between randomisation and the first 12-monthly visit (0-12 months), and then between 12-24 months and 24-36 months. In the analysis of the incidence, only those observations of a patient were included with no symptoms at the start of the three 12-month pairs, and for remission only those observations with the symptom under study present at the start. Each person could contribute 1-3 observations. Time (or net change over time) was a variable included only in the prevalence models. Net change over time was calculated using observations at months $0,12,24$ and 36. In the prevalence models, each person could participate with 1-4 observations. The GEE logistic regression model allows for within-person repeated measures and unequal numbers of observations, and was used to calculate odds ratios (OR) for risk factors associated with prevalence, incidence and remission of each individual symptom. Time invariant co-variates were as follows: treatment group; sex; age (10-yr units); body mass index (BMI; calculated as weight $(\mathrm{kg})$ divided by height $\left(\mathrm{m}^{2}\right)$ and divided into categories: underweight $=<18.5 \mathrm{~kg} \cdot \mathrm{m}^{-2}$; normal weight $=18.5-24.9 \mathrm{~kg} \cdot \mathrm{m}^{-2}$; overweight $=25.0-29.9 \mathrm{~kg} \cdot \mathrm{m}^{-}$ 2 ; obese $=\geqslant 30 \mathrm{~kg} \cdot \mathrm{m}^{-2}$ ); atopy (Phadiatop positive) and packyrs of smoking, all measured at randomisation (month 0 ). FEV1 $\%$ predicted (in $100 \mathrm{~mL}$ units), measured at the previous visit or at the start of a pair of visits, FEV1 12-month change between a pair of visits $(100 \mathrm{~mL})$ and change in daily number of cigarettes (per 10 cigarettes) smoked since previous visits or between visits were used as time-varying covariates. A variable of actual number of cigarettes smoked per day at time of randomisation was tested in the models instead of, or together with, pack-yrs, but gave no additional information and was omitted from current analyses. Interaction terms of sex with all variables were tested in all models to assess any differences in associations between males and females. Interaction terms of time with all the variables within the prevalence models were also tested. Additional models stratified by treatment were tested to investigate if findings within the sex models held true. Results are presented as OR with $95 \%$ confidence intervals (CI). Binary variables were evaluated using the Pearson Chi-squared test, and continuous and categorical variables by the Wilcoxon and Kruskal-Wallis tests, respectively, using the F distribution. The power of this 
study was based on the power calculated for the primary variable in the original EUROSCOP analysis, i.e. decline in FEV1. For this post hoc analysis a power calculation was not performed as it was not possible to change the numbers of patients observed. The power of the study to assess the outcomes under consideration can be assessed via the 95\% CI.

\section{RESULTS}

\section{Demographics}

The demographics and baseline characteristics of the population with complete data on symptoms and covariates are shown in table 1 . Males had a significantly greater number of pack-yrs of smoking than females, more frequently gave a positive Phadiatop test and were overweight or obese compared with females. Compared with males, females reported significantly more cough symptoms with a similar trend towards wheeze at randomisation. A total of 57 male and seven female patients gave up smoking during the study and sustained abstinence for four or more visits $(1 \mathrm{yr})$ and did not return to smoking. All other patients either smoked continuously or had failed attempts to give up smoking that lasted $<1$ yr. There were no significant differences in the proportions of male and female continuous smokers.

\section{Prevalence of symptoms}

The prevalence of symptoms at randomisation (month 0), stratified by sex, is shown in figure 1. Respiratory symptoms were rather prevalent in this population, ranging 34-59\% depending on type of symptom and sex. Females had a greater prevalence of all symptoms at all time-points except phlegm. However, it should be noted that by 36 months any significant differences had disappeared for all symptoms despite the underlying population proportions at each time-point remaining relatively stable.

\begin{tabular}{|c|c|c|c|}
\hline & Females & Males & p-value \\
\hline Subjects $n$ & 312 & 816 & \\
\hline Treatment with budesonide & $150(48)$ & $408(50)$ & 0.56 \\
\hline Pack-yrs of smoking & $30(22-38)$ & $39(29-51)$ & $<0.001$ \\
\hline Age yrs & $52(47-58)$ & $53(48-59)$ & 0.06 \\
\hline FEV $1 \%$ predicted & $81.1(70.2-88.6)$ & $79.2(68.3-88.4)$ & 0.42 \\
\hline BMI class $<18.5 \mathrm{Kg} \cdot \mathrm{m}^{-2}$ & $17(5)$ & $9(1)$ & $<0.001$ \\
\hline BMI class $18.5-24.9 \mathrm{Kg} \cdot \mathrm{m}^{-2}$ & $203(65)$ & $404(50)$ & \\
\hline BMI class $25.0-30.0 \mathrm{Kg} \cdot \mathrm{m}^{-2}$ & $75(24)$ & $322(39)$ & \\
\hline BMI class $30.1-43.9 \mathrm{Kg} \cdot \mathrm{m}^{-2}$ & $17(5)$ & $81(10)$ & \\
\hline Phadiatop positive & $30(10)$ & $173(21)$ & $<0.001$ \\
\hline Wheeze & $185(59)$ & $435(53)$ & 0.07 \\
\hline Dyspnoea & $124(40)$ & $290(36)$ & 0.19 \\
\hline Cough & $185(59)$ & $386(47)$ & $<0.001$ \\
\hline Phlegm & 112 (36) & 320 (39) & 0.31 \\
\hline
\end{tabular}

Data are presented as $n$ (\%) or median (interquartile range), unless otherwise stated. FEV1: forced expiratory volume in one second; BMI: body mass index. Binary variables were evaluated using the Pearson Chi-squared test, and continuous and categorical variables by the Wilcoxon and the Kruskal-Wallis tests, respectively, using the $\mathrm{F}$ distribution.

\section{Incidence and remission of symptoms}

The subsequent incidence and remission of symptoms by paired visits (i.e. from $0-12,12-24$ and 24-36 months) are shown in figure 2 . The number of males and females with new development (incidence) or remission of a symptom during any given time-period out of the number within the population from the same time-period is shown. Only wheeze showed a difference in incidence, with females reporting a greater incidence at 12-24 months. Females also reported greater remission for wheeze, dyspnoea and cough than males in the first 12 months. There were no other significant differences in incidence or remission.

\section{Risk factors for prevalence, incidence and remission of symptoms by sex}

Table 2 shows adjusted OR values for prevalence, incidence and remission of COPD symptoms by sex in association with significant risk factors. Table 2 shows only the key factors that had a significantly different effect in males and females for any prevalence, incidence or remission. This is indicated by + in table 2. Covariates of pack-yrs of smoking and atopy were tested in the models, but showed no significant differences by sex in association with symptoms. BMI showed a significant difference by sex for incidence of cough with females who were underweight showing increased incidence of cough (OR 12.23; 95\% CI 1.48-101.03) whilst males showed a decrease (OR $0.80 ; 95 \%$ CI $0.16-4.08$ ). However, these estimates are very wide for females due to small numbers with low BMI $(n=17)$. BMI showed no other significant differences by sex. Time, only included as a covariate in the prevalence model, showed that for every year of observation, males had a significant reduction in phlegm symptoms (OR 0.87; 95\%CI 0.82-0.93), an effect not seen in females (OR 0.99; 95\%CI 0.90-1.09). Age only showed a significant difference between males and females for incidence of dyspnoea, with females showing a significant reduction in new symptoms of dyspnoea for every 10-yr increase in age, recorded at the first visit (OR $0.47 ; 95 \% \mathrm{CI}(0.30-0.74)$ an effect not seen in males (OR 0.88; 95\% CI (0.70-1.10).

Table 2 shows that for every $100 \mathrm{~mL}$ increase in FEV1 at the previous visit, males had significantly reduced risk of wheeze and dyspnoea; this was not observed in females. For every $100 \mathrm{~mL}$ increase in FEV1 over time, males were significantly likely to have remission of their cough symptoms, whilst females were not.

Change in smoking (increasing the number of cigarettes by 10 per day during the year of observation) had a significantly different effect in males and females for development of new symptoms only. An increase in 10 cigarettes smoked per day was associated with an increased risk of developing new symptoms of wheeze and phlegm in males but not females, in whom the risk of wheeze even decreased. There were no significant differences by sex in the association of change in smoking with symptom prevalence or remission. Figure 3 illustrates how change in lung function $(100 \mathrm{~mL})$ and increasing the number of cigarettes smoked impacts upon symptom incidence, prevalence and remission. It demonstrates that, generally, there is little difference between males and females longitudinally for symptom incidence, prevalence or remission in association with either smoking or change in lung function after adjusting for confounding factors. 

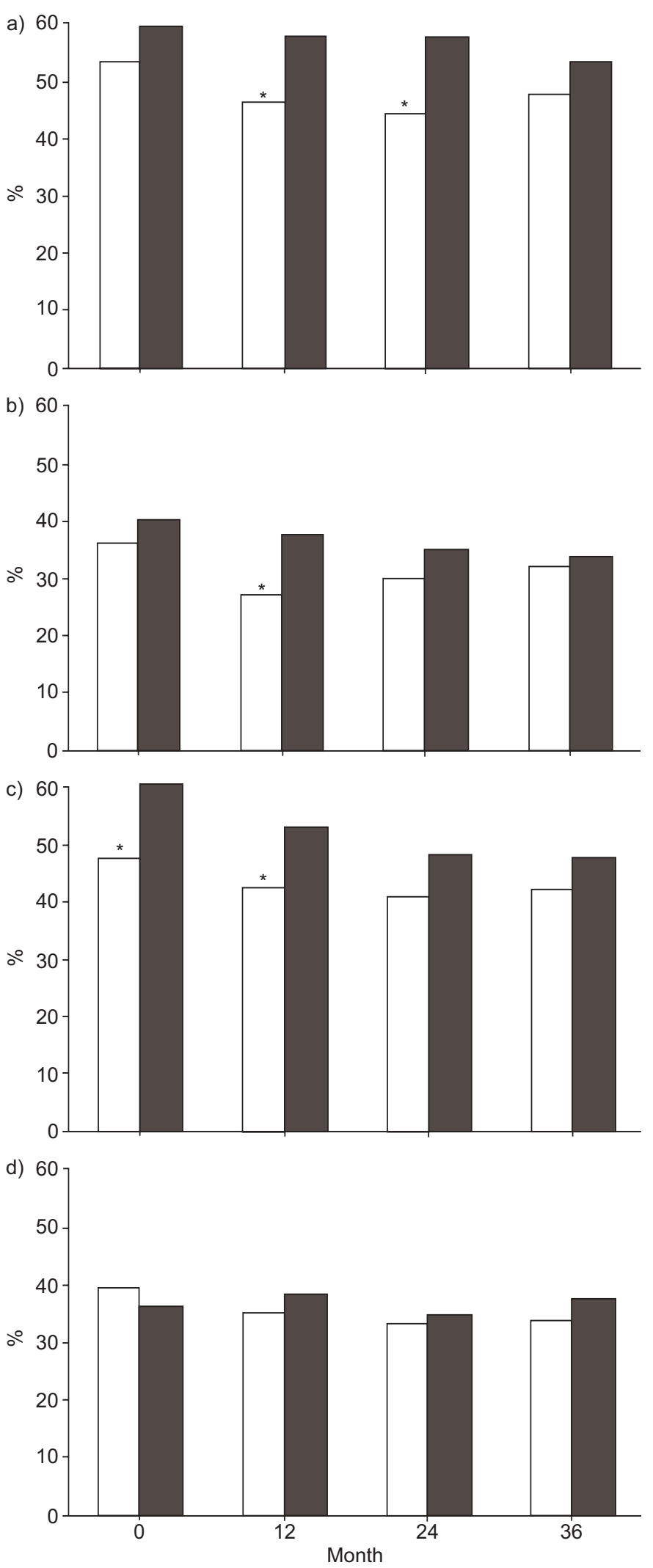

FIGURE 1. Prevalence of a) wheeze, b) dynspnoea, c) cough and d) phlegm over the study period for males $(\square)$ and females $(\square)$. The population per time period (numbers of males:females) is as follows. Month 0: 816:312; month 12: 675:260; month 24: 616:242; month 36: 594:226. *: $p<0.05$.
Treatment with budesonide significantly reduced phlegm in males but not females and had no differential effect on any other symptoms.

The results outlined above all refer to significant differences between males and females. However, $p$-values $<0.05$ demonstrate that there are also significant differences within sexes in some cases. For example, males who increase their FEV1 by $100 \mathrm{~mL}$ during any time period reduce their incidence and increase their remission of wheeze and cough during that year compared with those who do not show an improvement in FEV1. This effect is not observed in females. Similarly for males who have incremental increases in FEV1 over time compared with males who do not, incidence and prevalence of wheeze and cough is again reduced, an effect not experienced by females. Phlegm and dyspnoea also have greater remission for this change in lung function in males but not females.

\section{DISCUSSION}

The present study has shown that a person's sex can be important when assessing predictors of symptoms in male and female patients with mild-to-moderate COPD. The current authors performed stratified, adjusted analyses and discovered different risk factors for symptoms in males and females. Of particular note was the observed beneficial effect of higher FEV1 \% pred at randomisation and a greater increase in FEV1 over time on symptoms, and this was more frequently observed in males. Males additionally had reduced likelihood of phlegm, particularly so if treated with budesonide, which was not the case in females. Increasing the number of cigarettes smoked between visits was associated with more new symptoms of phlegm and wheeze in males only. While a large number of analyses were performed, the present authors do not believe that these findings are the result of multiple comparisons because only a priori hypotheses were tested that were postulated based on the literature.

Symptom prevalence over the study period showed significantly greater wheeze, dyspnoea and cough for females up to 24 months, but all significant differences had disappeared by 36 months, despite underlying population proportions remaining relatively static. The loss to follow-up would not be likely to explain the changes in proportion. The proportion of patients reporting symptoms in this trial remained high for both sexes at 36 months, ranging $30-75 \%$ according to symptom. Why the difference by sex disappears is not known, but it could be merely an artefact of the time-scale enforced by the study and could potentially reappear at a later time, as other studies have reported females report more symptoms of asthma and have different pain and tolerance thresholds [12]. However, differences by sex for remissions are only observed in the first year of the study, with females reporting greater remission, and this suggests that time may impact upon reporting. This study shows that symptom reporting in mildto-moderate COPD is similar between males and females longitudinally.

The findings that FEV1 \% pred values and the change in FEV1 are related to symptom incidence, prevalence and remission in male COPD patients indicates that, particularly in males, symptoms are a good predictor of disease status and/or underlying disease activity. To the current authors' knowledge, 
a)

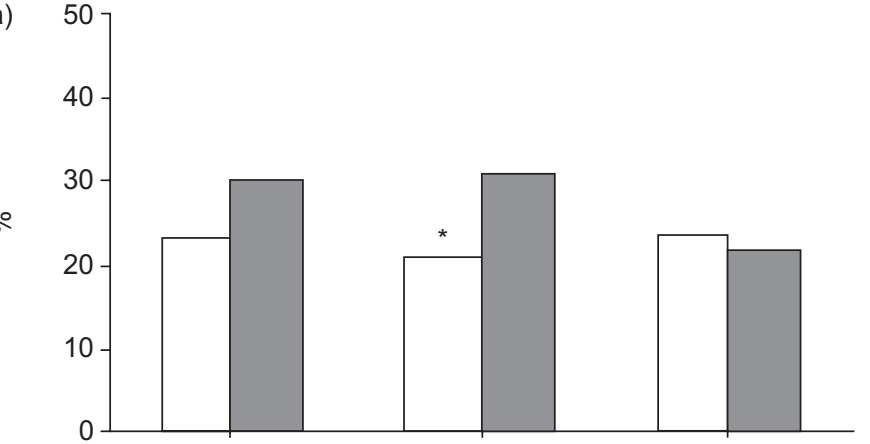

c)

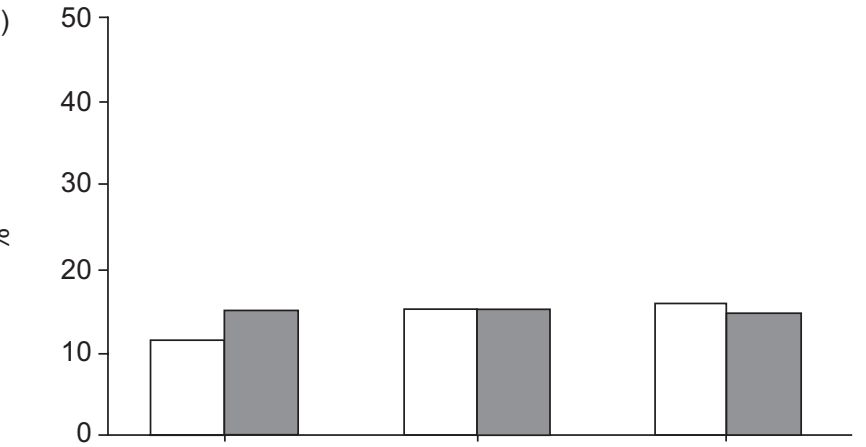

e) 50

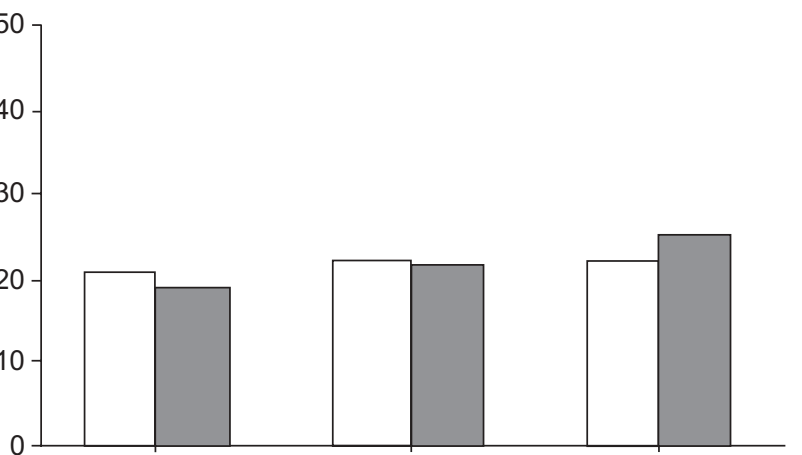

g)

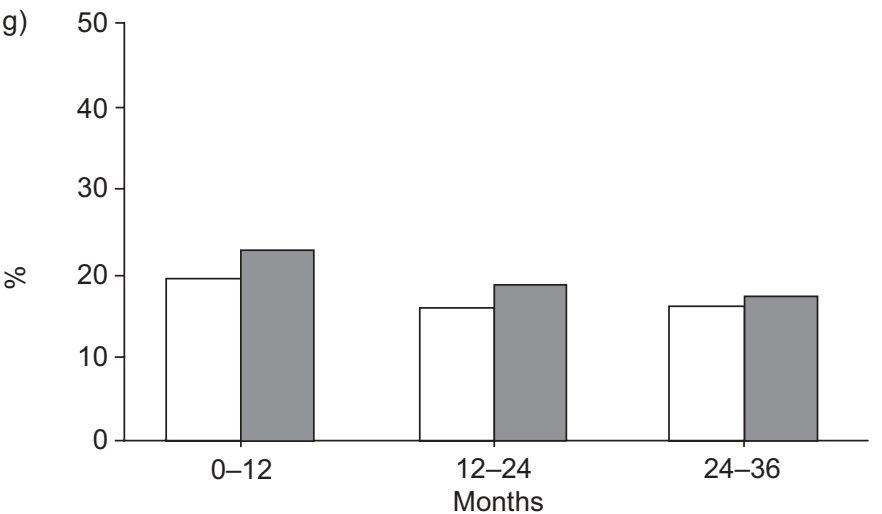

b)

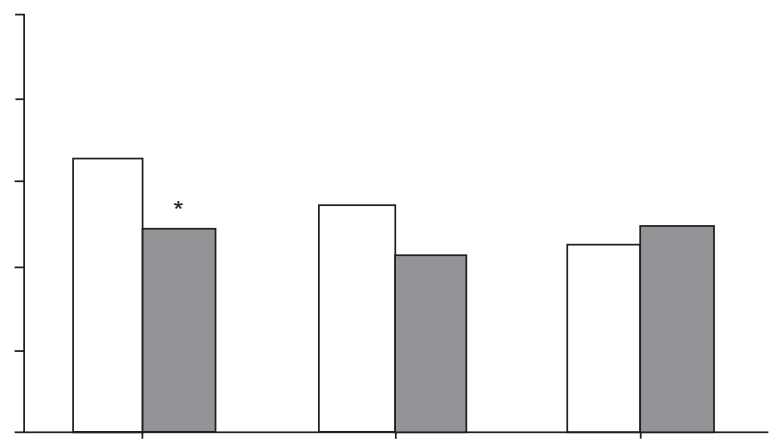

d)

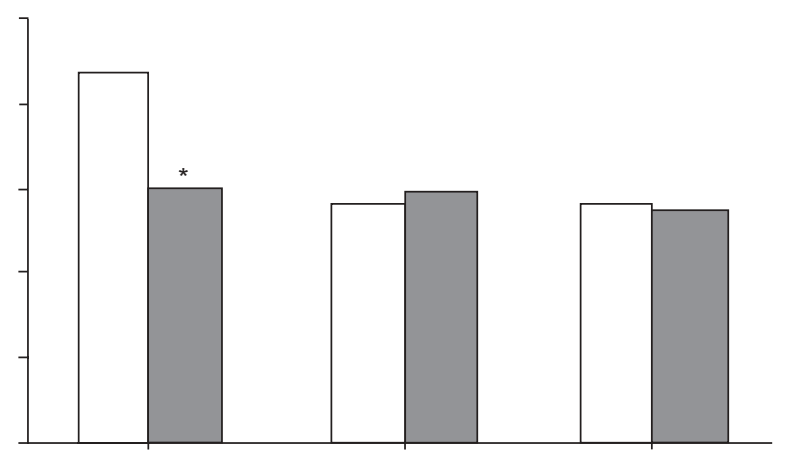

f)

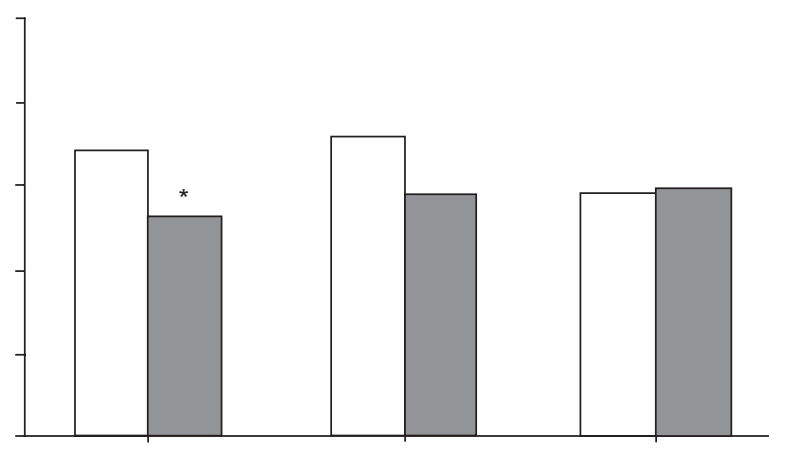

h)

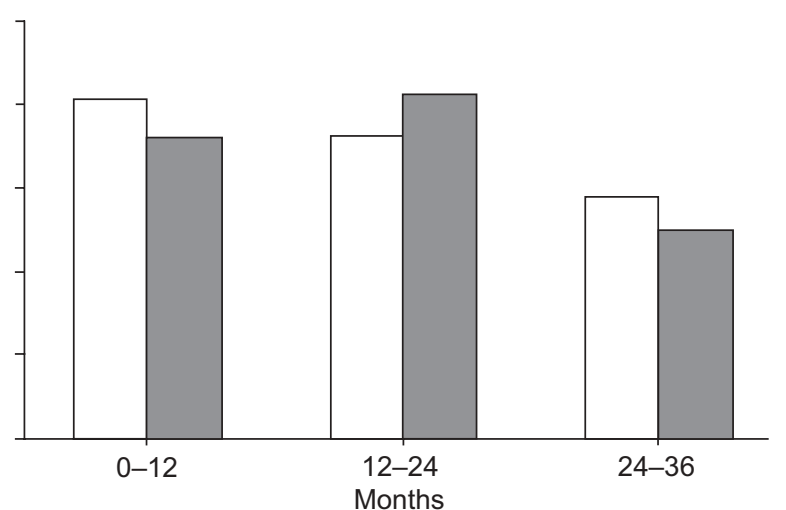

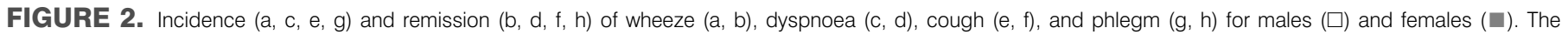

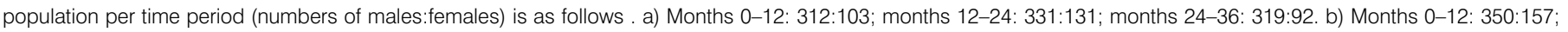

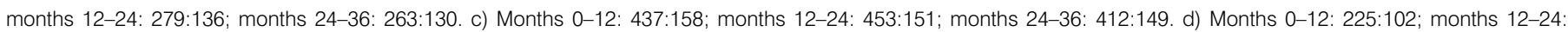

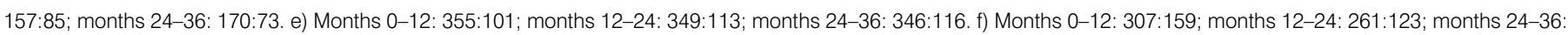

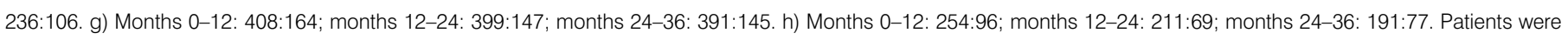

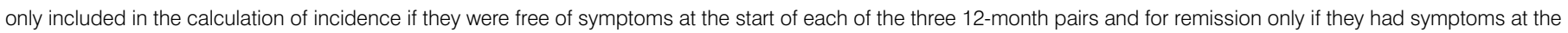
start of each of the three pairs. ${ }^{*}: p<0.05$. 


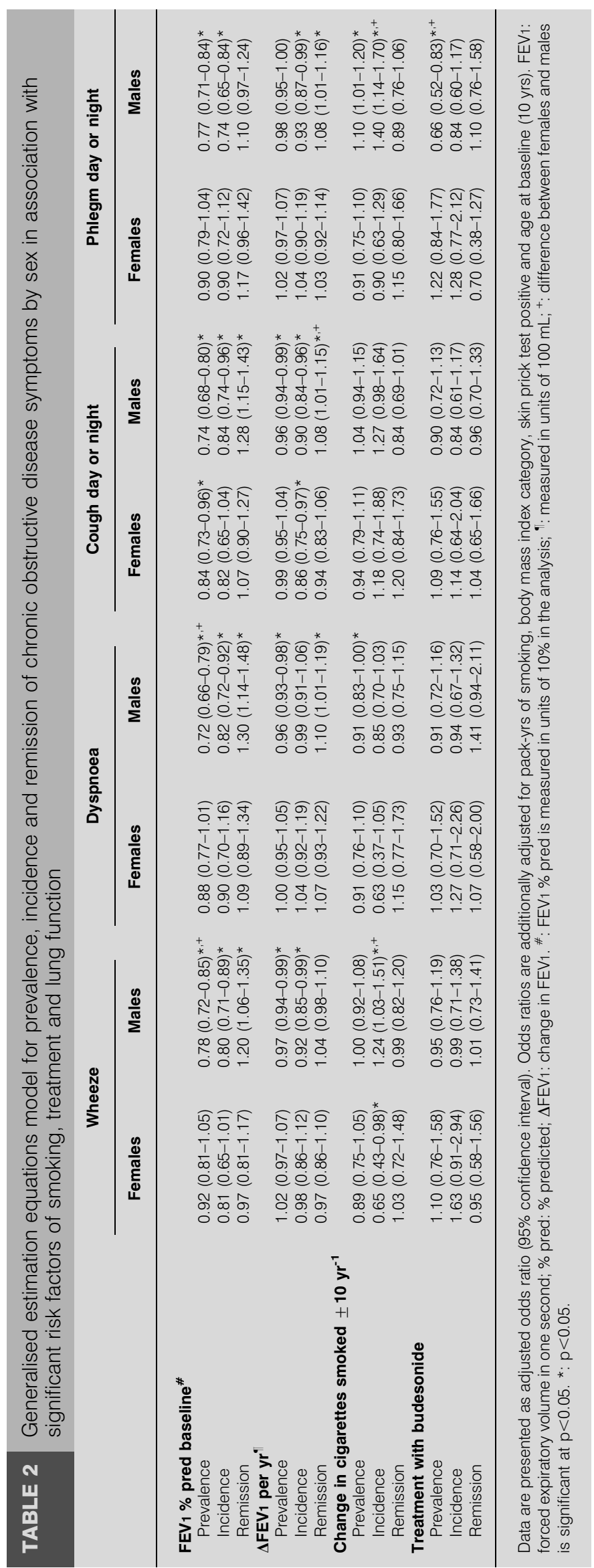

no other study to date has assessed how lung function predicts change in symptoms in COPD patients. WANG et al. [17] recently reported data from the Vlagtwedde/ Vlaardingen study in the Netherlands, studying subjects aged 15-35 yrs. In that study, it was found that the presence of all symptoms was associated with a reduced maximal FEV1 in males and having wheeze and dyspnoea was strongly predictive of lower VC. In females, only cough, wheeze and dyspnoea were associated with lower FEV1, but phlegm was not. In the longitudinal Tucson study with up to 14 yrs follow-up, SHERRILL et al. [16] found that symptomatic males had significantly lower FEV1 and forced vital capacity measures than symptomatic females. The relationship of cough and reduced lung function was only limited to males, supporting the present findings of a stronger male relationship between symptoms and lung function.

Stratified analyses showed that the risk of developing new symptoms caused by a change in smoking significantly differed by sex (table 2; fig. 3). Males exhibited a positive association, i.e. an increase in the number of cigarettes smoked was associated with an increased risk of developing new symptoms of wheeze and phlegm, whereas, conversely, wheeze was less likely to develop in females. The current authors hypothesise that a reason for the observed differences could be a different physiological response to the oxidation process resulting from exposure to the components of cigarette smoke. In the present study, the authors chose to show the effects associated with an increase in smoking, but, conversely, could have shown how a decrease in smoking affected symptoms, using the reciprocal data. Whichever data is used, there appears to be a difference by sex and this clearly requires further research.

Treatment with budesonide appeared to make little difference to symptoms, except with regard to phlegm, where prevalence was reduced, particularly in males. Previous studies were not designed to assess the impact of inhaled steroid use on symptoms in COPD; did not report symptoms [18]; and showed a beneficial effect on a composite score [20], on dyspnoea only [7], or did not show any significant effect [21]. However, none of these studies stratified analyses by sex. When this was carried out in the present study, the beneficial effect of budesonide treatment on phlegm was limited to males with an OR of 0.66 (95\% CI 0.52-0.83), compared to females with an OR of 1.22 (95\% CI 0.84-1.77). This outcome is unlikely to have been related to smoking, as all models were adjusted for smoking history and any changes in smoking between visits. When other smoking variables, such as giving up smoking since the last visit, giving up at baseline or absolute number of cigarettes smoked, were tested separately in the models, the results remained the same. Compliance with treatment was not measured in the EUROSCOP Study and there was possibly a difference in compliance between males and females. However, if compliance were greater in males, one would expect males to report significantly greater remission of symptoms compared with females throughout 3 yrs of followup. This was not the case, and females initially reported greater remission in all other symptoms in the first year of follow-up. Another more likely explanation may be a modifying effect of the sex of the patient on steroid effectiveness, as has been 


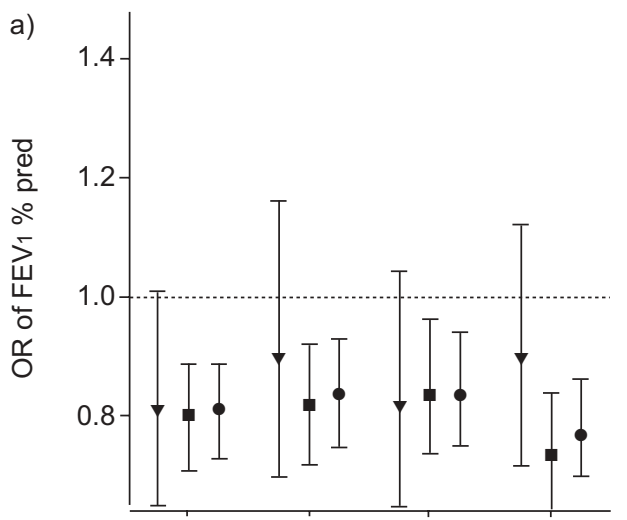

b)
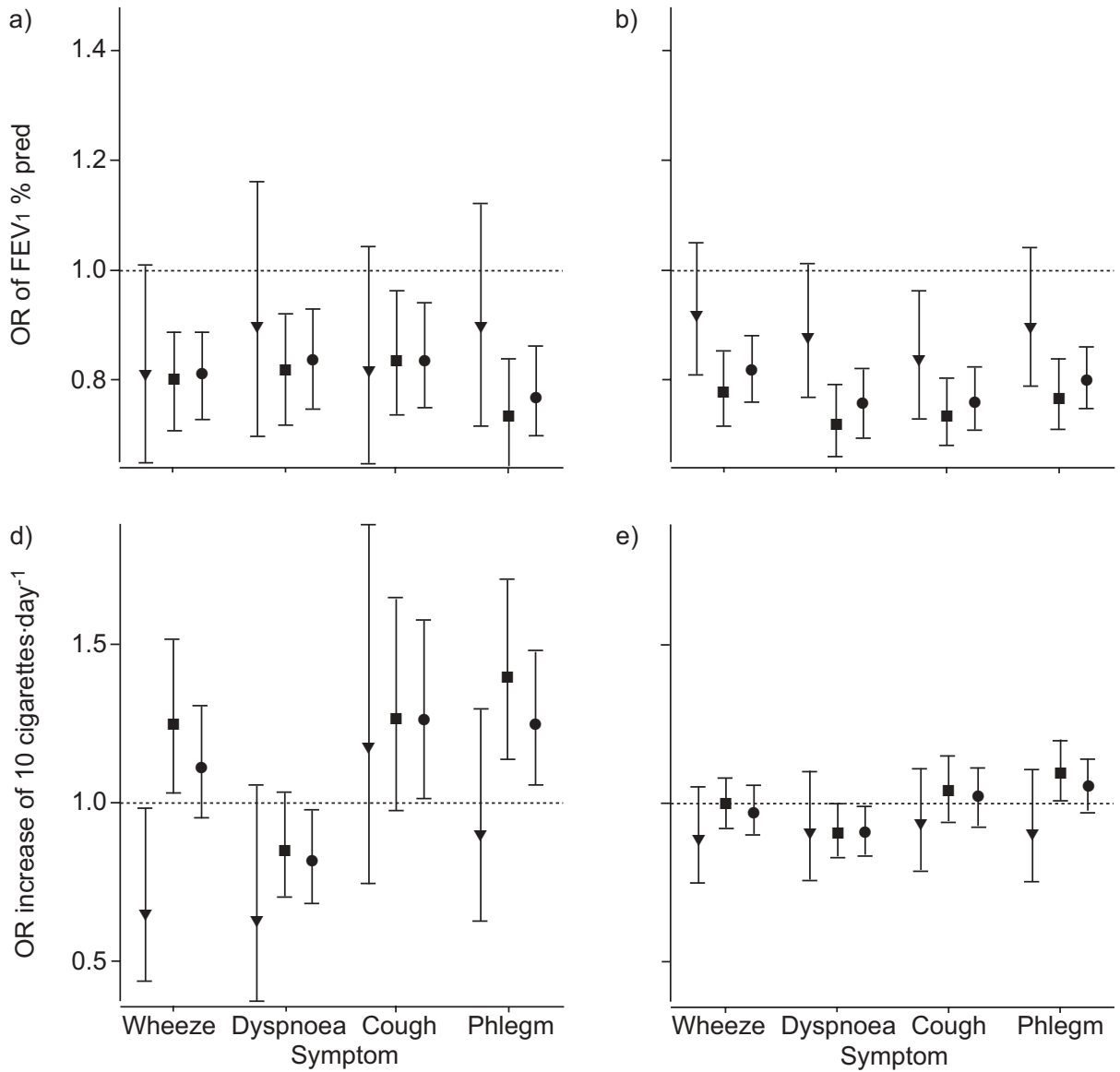

e)

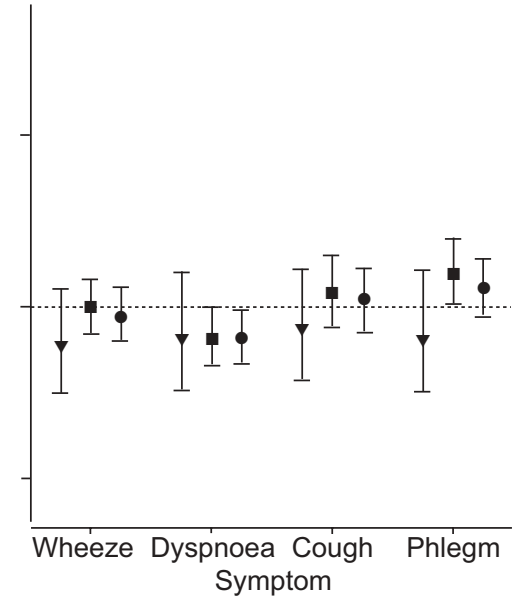

c)

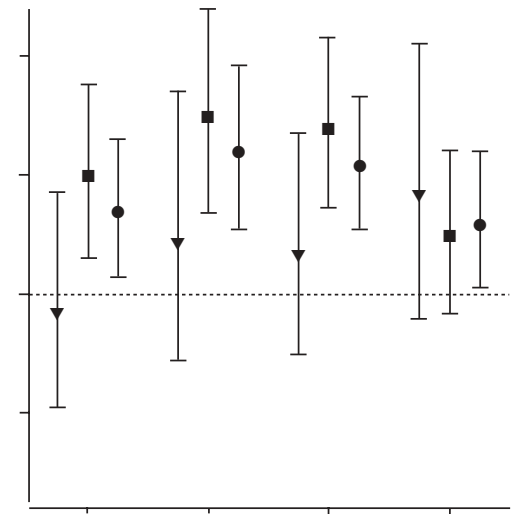

f)

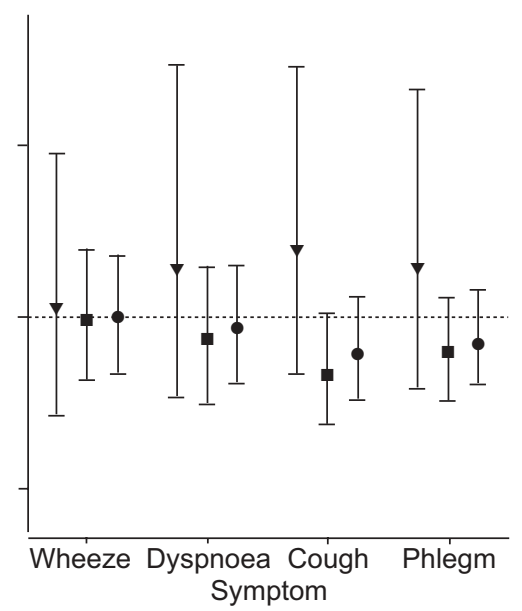

FIGURE 3. Odds ratios (OR) with $95 \%$ confidence limits are shown for symptoms at incidence $(a, d)$, prevalence (b, e) and remission (c, f) in association with forced expiratory volume in one second \% predicted (FEV1 \% pred; $100 \mathrm{~mL}$ ) and increase in smoking (per 10 cigarettes). The change in number of cigarettes smoked was calculated between visits and FEV 1 was calculated as change per year $(100 \mathrm{~mL})$ taken from the previous visit or the start of a pair of visits. OR are shown for males $(\boldsymbol{\square})$, females $(\mathbf{\Lambda})$ and both sexes combined

previously shown in asthma [24]. The results of the present study stress that future epidemiological and longitudinal clinical trials in COPD should analyse treatment effects on symptoms stratified by sex due to possible benefits that may be obscured by analysing both sexes together.

This study addressed, for the first time, the course of symptoms in males and females with mild-to-moderate chronic obstructive pulmonary disease, half of whom were treated with budesonide. A relatively high proportion of all patients reported symptoms throughout the study period, but the differences between males and females disappeared longitudinally. After adjusting for covariates that could confound the outcome, males were found to have a significantly stronger association between both higher per cent predicted forced expiratory volume in one second at randomisation and higher increase in forced expiratory volume in one second over time, and a reduced prevalence and incidence of symptoms. Treatment with budesonide reduced symptoms of phlegm in males only. Increasing the number of cigarettes smoked caused a contrasting effect by sex, with only males exhibiting an increase in wheeze and phlegm. These results show that in the clinical course and presentation of mild-tomoderate chronic obstructive pulmonary disease, the sex of the patient can matter and males show greater response longitudinally to both steroid treatment and smoking.

\section{ACKNOWLEDGEMENTS}

This manuscript is dedicated to R. Pauwels for his contribution to this work.

\section{REFERENCES}

1 Jansen DF, Schouten JP, Vonk JM, et al. Smoking and airway hyperresponsiveness especially in the presence of blood eosinophilia increase the risk to develop respiratory symptoms: a 25-year follow-up study in the general adult population. Am J Respir Crit Care Med 1999; 160: 259-264.

2 Krzyzanowski M, Lebowitz MD. Changes in chronic respiratory symptoms in two populations of adults studied longitudinally over 13 years. Eur Respir J 1992; 5: 12-20.

3 Krzyzanowski M, Robbins DR, Lebowitz MD. Smoking cessation and changes in respiratory symptoms in two populations followed for 13 years. Int J Epidemiol 1993; 22: 666-673.

4 Kanner RE, Connett JE, Williams DE, Buist AS. Effects of randomized assignment to a smoking cessation 
intervention and changes in smoking habits on respiratory symptoms in smokers with early chronic obstructive pulmonary disease: the Lung Health Study. Am J Med 1999; 106: 410-416.

5 Soriano JB, Maier WC, Egger P, et al. Recent trends in physician diagnosed COPD in women and men in the UK. Thorax 2000; 55: 789-794.

6 Ulrik CS. Smoking and mortality in women: "smoke like a man, die (at least) like a man". In: Buist S, Mapp CE, Rossi A, ed. Respiratory Disease in Women. Eur Respir Mono 2003; 25: 103-117.

7 The Lung Health Study Group, Effect of inhaled triamcinolone on the decline in pulmonary function in chronic obstructive pulmonary disease. N Engl J Med 2000; 343: 1902-1909.

8 Guerra S, Sherrill DL, Bobadilla A, Martinez FD, Barbee RA. The relation of body mass index to asthma, chronic bronchitis, and emphysema. Chest 2002; 122: 1256-1263.

9 Kanner RE, Connett JE, Altose MD, et al. Gender differences in airway hyperresponsivenes in smokers with mild COPD. Am J Respir Crit Care Med 1994; 150: 956-961.

10 Vestbo J, Prescott E, Lange P. Association of chronic mucus hypersecretion with FEV1 decline and chronic obstructive pulmonary disease morbidity. Am J Respir Crit Care Med 1996; 153: 1530-1535.

11 Weiss ST. Atopy as a risk factor for chronic obstructive pulmonary disease. Am J Respir Crit Care Med 2000; 162: 134-136.

12 Becklake M, Kauffmann F. Gender differences in airway behaviour over the human life span. Thorax 1999; 54: 1119-1138.

13 Merkus PJ, Borsboom GJ, van Pelt W, et al. Growth of airways and air spaces in teenagers is related to sex but not to symptoms. J Appl Physiol 1993; 65: 822-828.

14 Diepinigaitis $\mathrm{P}$, Khalid R. The influence of gender on cough reflex sensitivity. Chest 1998; 113: 1319-1321.
15 Sherman CB, Xu X, Speizer FE, Ferris BC, Weiss ST, Dockery DW. Longitudinal lung function decline in subjects with respiratory symptoms. Am Rev Respir Dis 1992; 146: 655-659.

16 Sherrill DL, Lebowitz MD, Knudson RJ, Burrows B. Longitudinal method for describing the relationship between pulmonary function, respiratory symptoms and smoking in elderly subjects: The Tucson Study. Eur Respir J 1993; 6: 343-348.

17 Wang X, Mensinga T, Schouten J, Rijken B, Weiss S. Determinants of maximally attained level of pulmonary function. Am J Crit Care Med 2004; 169: 941-949.

18 Burge PS, Calverley PM, Jones PW, Spencer S, Anderson JA, Maslen T. Randomised, double blind, placebo controlled study of fluticasone propionate in patients with moderate to severe chronic obstructive pulmonary disease: the ISOLDE trial. BMJ 2000; 320: 1297-1303.

19 Pauwels RA, Lofdahl C-G, Laitinen LA, et al. Long-term treatment with inhaled budesonide in persons with mild chronic obstructive pulmonary disease who continue to smoke. N Engl J Med 1999; 340: 1948-1953.

20 Renkema T, Schouten J, Koeter G, Postma D. Effects of long term treatment with corticosteroids in COPD. Chest 1996; 109: 1156-1162.

21 Vestbo J, Sorensen T, Lange P, Briz A, Torre P, Viskum K. Long-term effect of inhaled budesonide in mild and moderate chronic obstructive lung disease: a randomised controlled trial. Lancet 1999; 353: 1819-1823.

22 Yan J, Fine JP. Estimating equations for association structures. Stat Med 2004; 23: 859-880.

23 R Development Core Team. A Language and Environment for Statistical Computing. R Foundation for Statistical Computing. Vienna, Austria, 2006. www.R-project.org. Date last accessed: May, 17: 2006.

24 Convery R, Leitch D, Bromly C, Ward R, Bartlett G, Hendrick D. Effect of inhaled fluticasone propionate on airway responsiveness in treatment-naive individuals - a lesser benefit in females. Eur Respir J 2000; 15: 19-24. 